Research Article

openðaccess

\title{
Hysteroscopy: A Must in Endometrium Evaluation
}

\author{
Pramila Yadav ${ }^{1 *}$, Reena Wani ${ }^{2}$ \\ ${ }^{1}$ Assistant Professor, Department of Obstetrics and Gynecology, HBTMC and Dr R N Cooper Hospital, MUHS, \\ Mumbai, India \\ ${ }^{2}$ Addl. Professor and Head of Unit, Department of Obstetrics and Gynecology, HBTMC and Dr R N Cooper Hospital, \\ MUHS, Mumbai, India
}

\begin{abstract}
*Address for Correspondence: Dr. Pramila Yadav, Assistant Professor, Department of Obstetrics \& Gynaecology, HBTMC and R N Cooper Hospital, 302, Panthi Apartment, Tilak Nagar, MG Road, Road No- 3, Goregaon West, Mumbai400062, Nashik, India
\end{abstract}

E-mail: pramila411@gmail.com

Received: 26 Apr 2021/ Revised: 23 June 2021/ Accepted: 03 Aug 2021

\begin{abstract}
Background: Hysteroscopy is the gold standard for evaluation of uterine cavity can be utilized for varied gynaecological indications. Conventionally, hysteroscopy is performed under general anaesthesia but with technical advances over the years, it is now possible to do the procedure in ambulatory office settings with the same diagnostic accuracy.

Methods: We conducted a prospective clinical trial for a period of 2 years from January 2014 to December 2016 . In which, 60 cases were studied in which hysteroscopy was performed in the evaluation of the endometrium. 60 patients of age group $20-79$ years were included, who was admitted with a history of menorrhagia, infertility.

Results: The average age was 36.6 years. The maximum number of patients was in the age group $20-39$ years i.e. $50 \%$ followed by 40-59 i.e. $43.3 \%$. The commonest presentation was menorrhagia in $50 \%$ of cases followed by Primary infertility $18 \%$ Secondary infertility $13.3 \%$. Other presentations were polymenorrhea in $10 \%$ of cases, dysmenorrhea in $8.3 \%$.

Conclusion: Diagnostic hysteroscopy should be part of all cases of infertility and abnormal uterine bleeding as a routine procedure for better and efficient patient management Thus hysteroscopy is an important tool in the evaluation of patients with abnormal uterine bleeding. It does not only offers a quick, safe and accurate diagnosis, but, also operative hysteroscopy can be performed in the same sitting for removal of a polyp, fibroid, intrauterine adhesions, and misplaced IUCD
\end{abstract}

Key-words: Diagnostic, Endometrium, Hysteroscopy, Infertility, Menorrhagia

\section{INTRODUCTION}

Endometrial hyperplasia is defined as the irregular proliferation of the endometrial glands with an increase in the gland to stroma ratio, when compared with proliferative endometrium and hysteroscopy is considered to be a vital diagnostic tool for evaluation and assessment of it ${ }^{[1]}$. Hysteroscopy being the gold standard for evaluation of the uterine cavity can be utilized for varied gynaecological indications. Perimeno pause is characterized by its variability in hormonal levels ${ }^{\text {[2] }}$ with the increasing shortage of ovarian hormones and anovulation ${ }^{[3]}$.

\section{How to cite this article}

Yadav P, Wani R. Hysteroscopy: A Must in Endometrium Evaluation. SSR Inst. Int. J. Life Sci., 2021; 7(5): 2884-2889.

Access this article online
https://iijls.com/

The histological changes in the perimenopausal endometrium can be classified as non-proliferative lesions (atrophic, inactive, secretory, endometritis, endometrial metaplasia) or proliferative lesions: benign, noninvasive (endometrial polyps, endometrial and stromal hyperplasia) or malignant, invasive (endometrial cancer) ${ }^{[4,5]}$.

In a study of endometrial pathology in abnormal uterine bleeding, it has been found that the commonest pathology causing abnormal uterine bleeding (AUB) is the disordered proliferative pattern (20.5\%); other causes include benign endometrial polyp (11.2\%), endometrial hyperplasia (6.1\%), carcinoma $(4.4 \%)$ and chronic endometritis (4.2\%) ${ }^{[6]}$. Uterine leiomyomas or fibroids are benign smooth-muscle tumours of clonal origin ${ }^{[7]}$; they have an incidence that increases with age from menarche to perimenopause ${ }^{[8]}$. The more disturbing symptoms of premenstrual syndrome 
(physical symptoms-breast tenderness, abdominal bloating, nausea, headache, and emotional symptoms) ${ }^{[9]}$ can increase in severity and duration ${ }^{[4]}$. The hormonal instability during the perimenopausal period also increases migraine incidence ${ }^{[10]}$. Up to $14 \%$ of women experience irregular or excessively heavy menstrual bleeding ${ }^{[11]}$. Menorrhagia is heavy menstrual bleeding and is classically defined as a loss of $>80 \mathrm{ml} /$ cycle $^{[12,13]}$. Conventionally, hysteroscopy is performed under general anaesthesia but with technical advances over the years, it is now possible to do the procedure in ambulatory office settings with the same diagnostic accuracy ${ }^{[14]}$.

In general, hysteroscopy is one of the safest, easiest, and most quickly mastered surgical procedures in gynaecology. Hysteroscopy permits full visualization of the endometrial cavity and endocervix and helps diagnose focal lesions that are missed with endometrial sampling. Rapid visual inspection permits accurate diagnosis of atrophy, endometrial hyperplasia, polyps, fibroids, retained products of conception, and endometrial cancer [15]. There are many indications and few contraindications for office hysteroscopy. Hysteroscopy clarifies equivocal findings on TVUS and SIS. Complications from hysteroscopy are rare.

Mullerian anomalies causing infertility has been estimated to be the causal factor in as many as $10 \%$ to $15 \%$ of the couples seeking treatment. Moreover, other abnormal uterine findings have been found in $34 \%$ to $62 \%$ of infertile women ${ }^{[16]}$. Today, hysteroscopy is considered the gold standard for evaluating the uterine cavity in cases of both infertility and abnormal uterine bleeding. With improved endoscopic developments, it can be performed reliably and safely as an office procedure ${ }^{[15]}$. This study aimed to assess the role of hysteroscopy as a diagnostic tool in the evaluation of the endometrium and uterine cavity in various gynaecological conditions. Hysteroscopy offers a valuable extension of the gynaecologist's armamentarium. It can improve diagnostic accuracy and can permit better treatment of uterine diseases ${ }^{[17]}$ as it allows better planning of elective surgeries. After hysteroscopy, the elective surgery of the patient can be planned better ${ }^{[18]}$. The use of hysteroscopy in abnormal uterine bleeding is almost replacing blind curettage, as it "sees" and "decides" the cause. This is because the uterine cavity can be observed and the area in question can be curetted. It is an eye in the uterus ${ }^{[18,19]}$.

\section{MATERIALS AND METHODS}

This is prospective clinical trial was conducted at $\operatorname{Dr} \mathrm{R} \mathrm{N}$ Cooper Municipal General Hospital in Mumbai for a period of 2 years from January 2014 to December 2016 and comprised of 60 cases in which hysteroscopy was performed in the evaluation of the endometrium. Women of all age groups were included with a history of AUB (history of abnormal uterine bleeding), primary infertility, secondary infertility, missed Cu Twhereas patients with cervical infection and pregnant women were excluded.

The study was carried out in the department of obstetrics and gynaecology and 60 patients of age group 20-79 years were included, who was admitted with a history of menorrhagia, infertility excluding any demonstrable pelvic pathology like cancer of cervix, vagina or endometrium on clinical examination and active pelvic infection. Detailed history, examination and investigations were done. The hysteroscopic examination was done in all patients post-menstrually.

The technique included patients placed in dorsal lithotomy position and the perineum was cleaned with an antiseptic solution. A rigid hysteroscope (30 degrees, $3 \mathrm{~mm}$ ) was inserted in the uterus through the cervix. Normal saline was used as the distension media. Images were seen on the monitor and findings were documented. The patients then underwent dilatation and curettage and endometrium was sent for histopathologic examination. Hysteroscopy and histopathologic examinations were correlated accordingly.

Ethical Approval- Approval was taken from the Ethics Committee or the Institutional Review Board of HBTMC and Dr R N Cooper Hospital, India.

Statistical Analysis- The categorical data are summarized as frequency and percentage and continuous data as the median. The data is graphically represented using pie charts and bar diagrams.

\section{RESULTS}

The median age was 36.6 years. The maximum no. of patients was in the age group 20-39 years i.e. $50 \%$ followed by $40-59$ i.e. $43.3 \%$. Based on commonest indications as Per Fig. 1 for hysteroscopy it was noted that menorrhagia accounted for $50 \%$ of cases followed by Primary infertility (18.4\%) and then Secondary 
infertility $13.3 \%$. Other minor indications were polymenorrhea in $10 \%$ of cases as well as dysmenorrheal 8.3\% shows in Table 1.

Table 1: Indications of Hysteroscopic Procedures

\begin{tabular}{ccc}
\hline Variable & Frequency & Percent (\%) \\
\hline Menorrhagia & 30 & 50 \\
Primary Infertility & 11 & 18.4 \\
Secondary Infertility & 8 & 13.3 \\
Polymenorrhea & 6 & 10 \\
Dysmenorrhea & 5 & 8.3 \\
Total & 60 & 100 \\
\hline
\end{tabular}

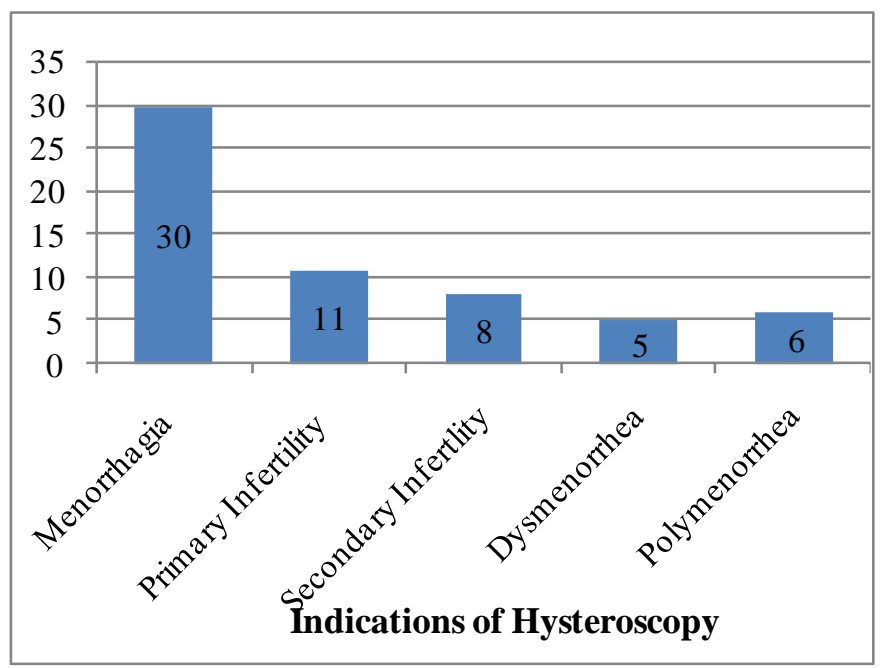

Fig. 1: Indications of Hysteroscopic Procedures

On hysteroscopic assessment, it was noted that $48.3 \%$ had normal endometrium and $18.3 \%$ has hyperplastic endometrium and $10 \%$ has atrophic endometrium followed by endometrial polyp and submucous fibroid accounting for $8.4 \%$ (Fig. 2). Endometrial septum and IUCD accounted for the least ranging for 3.3\% (Table 2).

Table 2: Findings based on hyteroscopic assessment

\begin{tabular}{ccc}
\hline Variables & Frequency & Percent (\%) \\
\hline Normal Endometrium & 29 & 48.3 \\
Hyperplastic Endometrium & 11 & 18.3 \\
Atrophic Endometrium & 6 & 10 \\
Hyperplastic Endometrium & 2 & 3.3 \\
septum & 5 & 8.4 \\
Endometrium polyp & 5 & 8.4 \\
\hline Submucous fibroid & 5
\end{tabular}

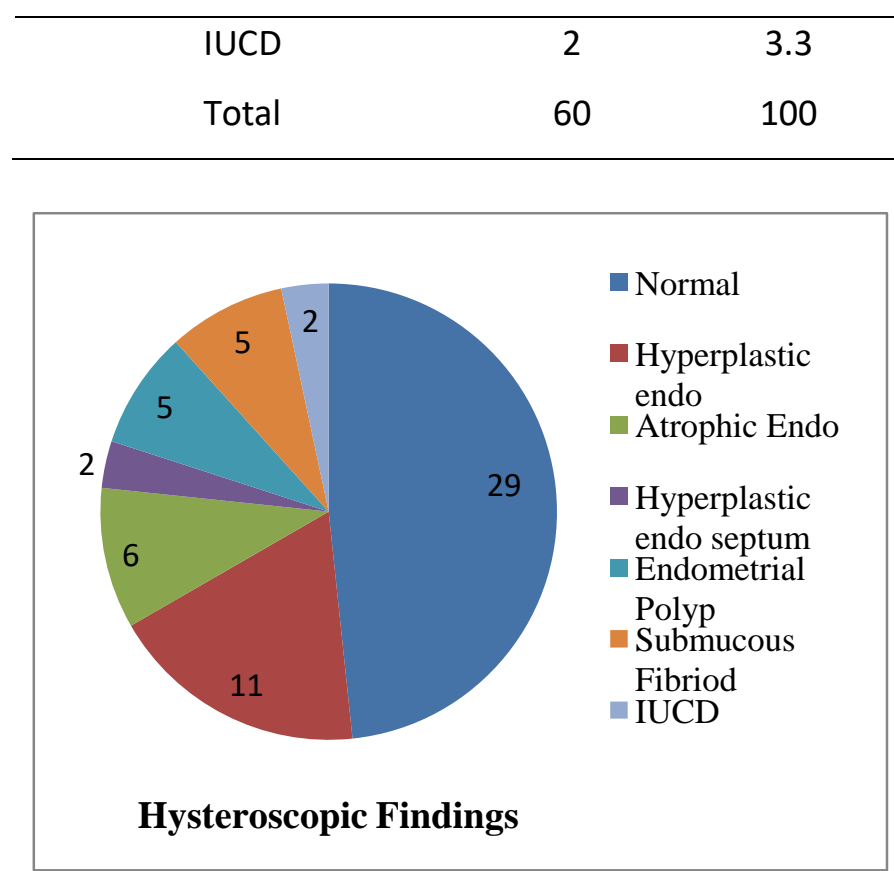

Fig. 2: Findings based on Hysteroscopic Assessment

On the evaluation of histopathology report, $51.7 \%$ had a normal endometrium and $18.4 \%$ had a hyperplastic endometrium followed by polyp and submucous fibroid accounting for $8.3 \%$. Atrophic endometrium was noted in $6.7 \%$ and septum as well as infective in $3.3 \%$ (Fig. 3 \& Table 3).

Table 3: Histopathology report based on hysteroscpoic assessment

\begin{tabular}{ccc} 
Variables & Frequency & $\begin{array}{c}\text { Percentage } \\
\text { (\%) }\end{array}$ \\
\hline Normal endometrium & 31 & 51.7 \\
Hyperplastic & 11 & 18.4 \\
Atrophic endometrium & 4 & 6.7 \\
$\begin{array}{c}\text { Hyperplastic } \\
\text { Endometrium Septum }\end{array}$ & 2 & 3.3 \\
Endometrium polyp & 5 & 8.3 \\
Submucous fibroid & 5 & 8.3 \\
Infective & 2 & 3.3 \\
Total & 60 & 100 \\
\hline
\end{tabular}

In the majority of cases $43.3 \%$, total intravenous anaesthesia was given and general anaesthesia in $31.6 \%$ followed by spinal anaesthesia in $25 \%$ (Table 4 ). 


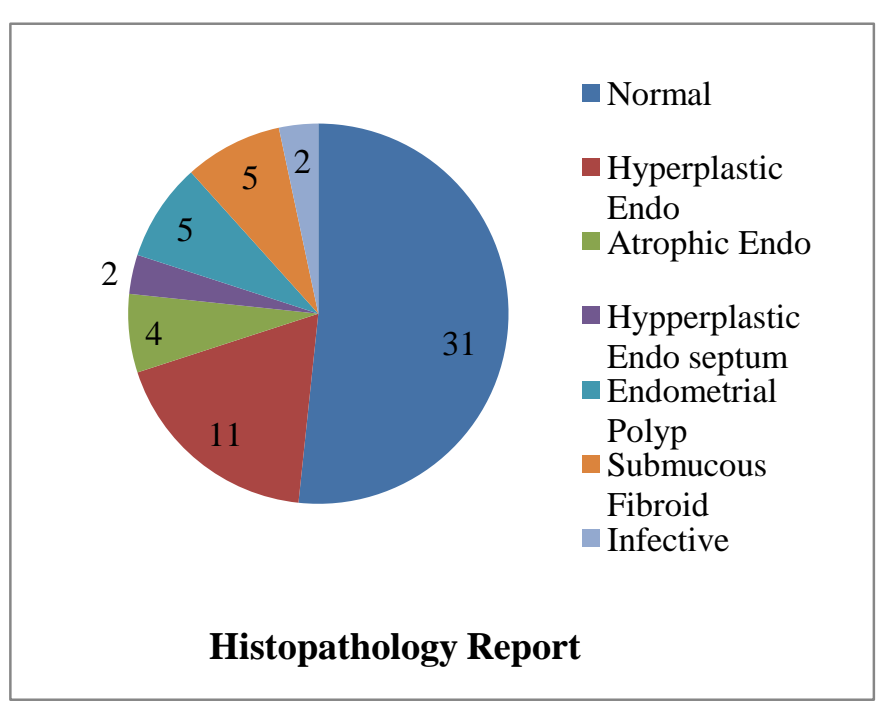

Fig. 3: Histopathology Report based on Hysteroscopic Assessment

Table 4: Type of Anaesthesia used

\begin{tabular}{ccc}
\hline GA (\%) & SA (\%) & TIVA (\%) \\
\hline 19 & 15 & 26 \\
31.6 & 25 & 43.3 \\
\hline
\end{tabular}

On the assessment of associated medical co-morbidities, $5 \%$ patients were diabetic, $10 \%$ had hypertension, $6.6 \%$ had thyroid dysfunction and $3 \%$ had both hypertension and diabetes. The complications noted was one patient had uterine perforation as a complication of hysteroscopy, but the rent was small and did not require any treatment except for monitoring. Rest all cases no complication was observed. There was no procedurerelated mortality seen in the study.

\section{DISCUSSION}

Hysteroscopy is a valuable, simple, low-risk technique that allows adequate visualization of the entire uterine cavity. Hysteroscopy increases the accuracy of clinical diagnosis and may serve as an adjunct in the treatment of patients with specific intrauterine pathological conditions ${ }^{[20]}$. In patients with abnormal uterine bleeding and infertility, hysteroscopy provides the possibility of immediate diagnosis and effective treatment. During hysteroscopy, a biopsy can be taken from the suspected area with precision and endometrial polyp can also be removed at the same time. In this study commonest presentation was menorrhagia followed by primary and secondary infertility.
Normal hysteroscopic findings were observed in 48.3 of the cases, which were similar to the study by Dasgupta et al. [17] and Sheetal et al. ${ }^{[19]}$, who observed normal hysteroscopic findings in $50 \%$ and $39.1 \%$, respectively. Uterine cavity evaluation, 11 patients presented with primary infertility, 8 patients with secondary infertility, and 18 patients were normal uterine cavity on hysteroscopy. One patient was an abnormal uterine cavity diagnosed as the unicornuate uterus.

In AUB Most common abnormality detected was hyperplastic endometrium i.e. $18.4,6 \%$ which was close to that observed in Jyotsana et al. ${ }^{[22]}$ and Dasgupta et al. ${ }^{[17]}$, which was $22.6 \%$ and $30.6 \%$, respectively. Atrophic endometrium was present in 6 patient's i.e. $10 \%$ of cases in our study, which was close to that observed in Sheetal et al. ${ }^{[19]}$; Acharya et al. ${ }^{[21]}$, which was $8 \%$. The hyperplastic endometrium septum of 2 patients was $3.3 \%$. Acharya et al. [21] had obtained a diagnostic accuracy of $100 \%$ in endometrium polyp by hysteroscopy. In this study, all 5 cases of endometrium polyp were diagnosed by hysteroscopy.

Endometrium polyp and submucous fibroid were found in 5 patients i.e. $8.3 \%$. On hysteroscopy, we could find IUCD in the uterine cavities of 2 patients. All these IUDs were removed grasping Forceps and hooks. In correlation with the HPE report, it was noted that endometrium appeared to be normal on hysteroscopy in 29 cases. The same was confirmed by histopathology. Hyperplastic endometrium was found in 11 cases. The same was confirmed by histopathology. The endometrium appeared atrophic on hysteroscopy in 6 cases that were confirmed by histopathology in 4 cases, while the rest 2 cases showed normal endometrium. Endometrium polyp and Submucous fibroid were found in 5 cases on hysteroscopy. The same was confirmed by histopathology. Hysteroscopy is $100 \%$ accurate for intrauterine pathologies like polyp and submucous fibroid. Thus, Hysteroscopy is an important tool in the evaluation of patients with abnormal uterine It not only offers a quick, safe and accurate diagnosis, but, also operative hysteroscopy can be performed in the same sitting for removal of a polyp, fibroid, intrauterine adhesions, and misplaced IUCD.

Just like other surgical procedures, hysteroscopy may have minor complications but $99 \%$ of these complications are preventable and treatable. Hysteroscopic surgery undoubtedly has a changed the 
treatment modality in gynaecology. Although endoscopic surgery today is considered a specialized field, it will over some time, become part of routine gynaecological surgery ${ }^{[23]}$. Since neither ultrasonography nor curettage has any curative effect, hysteroscopy must be viewed as the gold standard for evaluation and treatment of abnormal uterine bleeding ${ }^{[24]}$. And since it also is significantly cheaper than inpatient examination thus patients undergoing examinations as outpatients have significantly less time work and faster recovery ${ }^{[25]}$.

\section{CONCLUSIONS}

Diagnostic hysteroscopy should be part of all cases of infertility and abnormal uterine bleeding as a routine procedure for better and efficient patient management as in patients with abnormal uterine bleeding, hysteroscopy has made it possible to attain immediate diagnosis thus helping in prompt and effective treatment. It allows finding out the source of bleeding and perform a directed biopsy of the suspected area.

Hysteroscopy has more accuracy (100\%) for identifying intrauterine pathologies like endometrial polyp, submucous myoma and misplaced $\mathrm{Cu}$-Tin comparison to endometrial biopsy or dilatation and curettage alone. Thus the introduction of office hysteroscopy with directed biopsies can help minimise the need for hospital diagnostic dilatation and curettage.

\section{CONTRIBUTION OF AUTHORS}

Research concept- Dr Pramila Yadav

Research design- Dr Reena Wani

Supervision- Dr Reena Wani

Materials- Dr Pramila Yadav

Data collection- Dr Pramila Yadav

Data analysis and interpretation- Dr Pramila Yadav

Literature search- Dr Arvind Muley

Writing article- Dr Pramila Yadav

Critical review- Dr Reena Wani

Article editing- Dr Pramila Yadav

Final approval- Dr Pramila Yadav

\section{REFERENCES}

[1] Royal College of Obstetricians and Gynaecologists [Internet]. Endometrial Hyperplasia, Management of (Green-top Guideline No. 67). Published on
26/02/2016. Available from: https://www.rcog.org. uk/en/guidelines-research-services/guidelines/ gtg67/.

[2] Nilsson L. The hormonal situation in the perimeno pausal period. Acta Obstet Gynecol Scand Suppl., 1985; 130: 9-11.

[3] Huston JE, Lanka DL. Changes in women's health after 35. $2^{\text {nd }}$ ed. Oakland: New Harbinger Publications; 2001.

[4] Boon J, Van de Putte SC, Scholten PC, Heintz AP. Histological patterns in endometrial samples from perimenopausal women. Maturitas., 1999; 32(3): 155-59.

[5] Doraiswami S, Johnson T, Rao S, Rajkumar A, Vijayaraghavan J, et al. Study of endometrial pathology in abnormal uterine bleeding. J Obstet Gynecol India, 2011; 61(4): 426-30.

[6] Hashimoto K, Azuma C, Kamiura S, Kimura T, Nobunaga $T$, et al. Clonal determination of uterine leiomyomas by analyzing differential inactivation of the X-chromosome-linked phosphoglycerokinase gene. Gynecol Obstet Inves., 1995; 40: 204-08.

[7] Ross RK, Pike MC, Vessey MP, Bull D, Yeates D, et al. Risk factors for uterine fibroids: reduced risk associated with oral contraceptives. Br Med J., 1986; 293: 359-62.

[8] Chung SH, Kim TH, Lee HH, Lee A, Jeon DS, et al. Premenstrual syndrome and premenstrual dysphoric disorder in perimenopausal women. J Menopausal Med., 2014; 20(2): 69-74.

[9] Ibrahimi K, Couturier EGM, et al. Migraine and perimenopause. Maturitas., 2014; 78: 277-80.

[10]Hallberg L, Högdahl AM, Nilsson L, Rybo G. Menstrual blood loss-A population study. Variation at different ages and attempts to define normality. Acta Obstet Gynecol Scand., 1966; 45: 320-51.

[11]Cole S. Menstrual blood loss and haematological indices. J Reprod Fertil., 1971; 27: 158.

[12]Tangri M, Lele P, Kapur K, Kapur A, Chhabra N, et al. Role of office hysteroscopy in gynecology: Retrospective observational study at a tertiary care hospital. Int J Reprod Contracept Obstet Gynecol., 2017; 6(1): 111-16. doi: 10.18203/23201770. ijrcog20164642.

[13] Hysteroscopy. (n.d.). Available from: https://www. sciencedirect.com/topics/nursing-and-healthprofessions/hysteroscopy, Retrieved Feb 08, 2021. 
[14]Brown SE, Coddington CC, Schnorr J, Toner JP, Gibbons $W$, et al. Evaluation of outpatient hysteroscopy, saline infusion hysterosonography, and hysterosalpingography in infertile women: a prospective, randomized study. Fertil Steril., 2000; 74(5): 1029-34. doi:10.1016/s0015-0282(00)01541-7.

[15]Sahu L, Tempe A, Gupta S. Hysteroscopic evaluation in infertile patients: a prospective study. Int J Reprod Contracept Obstet Gynecol., 2012; 1(1): 37-41

[16]Patil SG, Bhute SB, Inamdar SA, Acharya NS, Shrivastava DS. Role of diagnostic hysteroscopy in abnormal uterine bleeding and its histopathologic correlation. J Gynecol Endosc Surg., 2009; 1(2): 98104. doi: 10.4103/0974-1216.71617.

[17]Dasgupta S, Chakraborty B, Karim R, Aich R, Mitra P, et al. Abnormal uterine bleeding in peri-menopausal age: Diagnostic options and accuracy. J Obstet Gynaecol India, 2011; 61(2): 189-94.

[18]Arslan S, Aytan H, Gunyeli I, et al. Office hysteron scopic evaluation of endometrium: Can we hit the target. Arch Gynecol Obstet., 2004; 271: 200-02.

[19]Patil SG, Bhute SB, Inamdar SA, Acharya NS, et al. Role of diagnostic hysteroscopy in abnormal uterine bleeding and its histopathologic correlation. J Gynecol Endosc Surg., 2009; 1(2): 98-104.
[20]Menon MKK, Devi PK, Rao KB. Postgraduate Obstetrics and Gynecology. India: Orient Longman, 1982; pp. 253.

[21] Acharya V, Mehta S, Randar A. Evaluation of dysfunctional uterine bleeding by TVS, hysteroscopy and histopathology. J Obstet Gynaecol India, 2003; 53: 170-77.

[22]Jyotsana DR, Manhas K, Sharma S. Role of Hysteroscopy and Laparoscopy in Evaluation of Abnormal Uterine Bleeding. JK Sci., 2004; 6(2): 2327.

[23]Taneja SP. Hysteroscopy: Past, present and future. Med J Armed Force India, 2002; 58: 293-94. doi: 10.1016/S0377-1237(02)80079-X.

[24]Gimpelson RJ, Whalen TR. Hysteroscopy as gold standard for evaluation of abnormal uterine bleeding. Am J Obstet Gynecol., 1995; 173(5): $1637-$ 38. doi: 10.1016/0002-9378(95)90670-3.

[25]Symonds I. Ultrasound, hysteroscopy and endometrial biopsy in the investigation of endometrial cancer. Best Pract Res Clin Obstet Gynaecol., 2001; 15(3): 381-91. doi: 10.1053/beog.2000.0183. 